\title{
Sensitivity and performance characteristics of a direct PCR with stool samples in comparison to conventional techniques for diagnosis of Shigella and enteroinvasive Escherichia coli infection in children with acute diarrhoea in Calcutta, India
}

\author{
SHANTA DUTTA, A. CHATTERJEE*, P. DUTTA, K. RAJENDRAN, S. ROY, K. C. PRAMANIK \\ and S. K. BHATTACHARYA
}

National Institute of Cholera and Enteric Diseases, Beliaghata, Calcutta 700010 and * University College of Medicine, Calcutta 700024, India

\begin{abstract}
As the sensitivity of the conventional techniques for identifying Shigella spp. and enteroinvasive Escherichia coli (EIEC) causing dysentery cases is low, a PCR assay was evaluated in this study. Analytical sensitivity $\left(2 \times 10^{2} \mathrm{cfu}\right)$ of the PCR technique was obtained by artificially spiking negative stool samples with a standard strain of $S$. flexneri type 2 , then determining the detection limit. Specificity $(\mathbf{1 0 0 \% )}$ of the method was determined by testing a number of known Shigella and EIEC strains and organisms other than Shigella spp. A total of 300 stool samples collected from children with acute diarrhoea was plated on to two selective agar media after enrichment in Luria broth. Shigella spp. were isolated from 7.7\% (23 of 300) and EIEC from 1\% (3 of 300) patients. All enriched stool samples were subjected to PCR to amplify the target sequence of invasive plasmid antigen (ipa) $H$ locus, a multicopy element found on the chromosome and invasion plasmid. The stool PCR was positive in 24 of the 26 culturepositive and in 22 culture-negative stools, thus detecting the presence of Shigella spp. or EIEC in $15.3 \%$ (46 of 300) of diarrhoea cases. When an ial probe was used for colony hybridistion with enriched stool cultures blotted on to membranes, 9.6\% (29 of 300) of dysentery cases were identified as being caused by Shigella spp. or EIEC. Thus the sensitivity of enriched stool culture, colony hybridisation and enriched stool PCR was found to be $54 \%, 60 \%$ and $96 \%$, respectively, when each of the methods was compared to the total microbiologically confirmed cases of dysentery. It was also observed that only 38\% (48 of 126) of acute bloody dysentery cases actually had shigella or EIEC infection, as confirmed by laboratory methods. Moreover, this PCR assay could identify a number of untypable Shigella strains (Sh OUT), which would have remained undiagnosed had this assay not been used.
\end{abstract}

\section{Introduction}

Shigella species and enteroinvasive Escherichia coli (EIEC), the principal aetiological agents of dysentery, remain endemic in developing countries and may cause outbreaks in developed countries. As shigellosis in children often leads to growth retardation, anaemia and other sequelae, early detection and treatment with appropriate antibiotic is recommended [1]. Culture

Received 25 Oct. 2000; revised version accepted 19 Feb. 2001.

Corresponding author: Dr S. Dutta (e-mail: niced@cal2. vsnl.net.in. methods used for the identification of shigellae from stool samples are relatively inefficient, time-consuming, labour intensive and the diagnosis often remain obscure due to the presence of low numbers of causative organisms, competition from other commensal organisms and inappropriate sample collection. If samples are collected after antibiotic therapy, the growth of the organism may be impaired as a result of sublethal injuries by the antibiotics. Recent diagnostic molecular biological techniques have overcome some of these problems.

The polynucleotide ial probe [2], derived from the large 'invasion' plasmid, is used to identify invasive 
shigellae and EIEC by nucleic acid hybridisation. Despite being specific, the method is less sensitive when used directly with 'blotted' stool specimens or with colonies from solid media blotted on to the membrane. Furthermore, spontaneous loss of the invasion plasmid during in-vitro growth of the organism or selective deletion of invasion-associated genes may restrict the usefulness of such probes as general diagnostic tools and may give rise to false-negative results with a culture-positive sample [3]. However, a second DNA probe, derived from the S. flexneri ipaH gene, a multiple-copy element found on the large invasion plasmid and the chromosome that encodes a $60-\mathrm{kDa}$ antigen, is more sensitive in its ability to detect shigellae and EIEC strains [4]. On the other hand, several PCR protocols have been developed for direct detection of shigellae and allied organisms in food and faecal samples [5,6]. A PCR assay is also able to distinguish between shigellae and EIEC in faeces [7].

In one PCR assay, the invasion plasmid antigen $\mathrm{H}$ gene $(i p a H)$ sequence has been amplified for the diagnosis of dysentery cases [8]. This PCR system is very effective for diagnosing cases of dysentery in studies conducted in countries like Thailand, Bangladesh and Brazil [9-12]. In a study from Thailand [9], the system increased the diagnosis of shigella and EIEC infections by $45 \%$ among patients with dysentery, when compared with bacteriological methods. This PCR method was also found to be sensitive and useful in a study in Bangladesh [11]. In Thailand, it also proved to be sensitive among patients who had received antibiotics when the samples were tested several days after the onset of illness $[8,9]$. In Calcutta, Shigella spp. were isolated from $5-8 \%$ of children with acute diarrhoea [13] as determined by culture methods. Studies of this type have not been performed in India for the rapid detection of dysentery cases caused by Shigella spp. or EIEC by molecular methods such as PCR in an epidemiological setting.

The present study was initiated to determine the analytical sensitivity and specificity of a previously used ipaH PCR diagnostic assay system in an Indian situation. The study also compared the performance characteristics of this PCR system and other conventional microbiological techniques to determine the identifiable disease frequency in hospitalised children with acute diarrhoea in Calcutta.

\section{Materials and methods}

Bacterial strains used to determine the specificity of the PCR assay

A total of 170 bacterial strains, including 64 of known serotypes of Shigella spp. (S. dysenteriae 8, S. flexneri 24, S. boydii 12, S. sonnei 20) and 106 non-Shigella bacterial strains - Salmonella spp. 25, enterovirulent E. coli 41 (including 7 EIEC strains) and avirulent $E$. coli 40 - were included for testing the specificity of the PCR system. All Shigella strains were isolated from acute dysentery cases in Calcutta between 1990 and 1997, confirmed biochemically by conventional microbiological methods and with the API 20E system (bioMérieux, France), and serotyped by slide and tube agglutination with commercially available group- and type-specific antisera (Denka Seiken, Japan). S. flexneri type 2 (no. SD 70) and enteroinvasive E. coli $\mathrm{O} 112$ ac (no. SD 9) were used as positive controls in each batch of tests.

\section{Plasmid profiles of the strains}

To determine the plasmid profiles, plasmids were extracted from known Shigella and EIEC local isolates by standard methods [14] and separated by electrophoresis on agarose $1 \%$ gels, stained with ethidium bromide and visualised under UV transillumination (BioRad, USA). Plasmids were also extracted from untypable Shigella strains (Sh OUT) identified during this study.

\section{Oligonucleotide probe and DNA hydridisation}

The ial probe [2] was derived from the nucleotide sequence of a 2.5-kb HindIII fragment of an EIEC invasion plasmid, by standard technique [15]. The Hybond $\mathrm{N}+$ nylon membranes were blotted with enriched bacterial or stool cultures, placed on to agar media and incubated at $37^{\circ} \mathrm{C}$ for $24 \mathrm{~h}$ for the macrocolonies to grow. Membranes were baked at $80^{\circ} \mathrm{C}$ for $2 \mathrm{~h}$ to fix the DNA to the membrane. Colony hybridisation was performed with the ial probe labelled with the ECL direct nucleic acid labelling system (Amersham, Life Science) following the manufacturer's instructions. Positive samples were detected by signals deveoped in autoradiograms with ECL detection reagents.

\section{Oligonucleotide primers and PCR}

As described previously [12], oligonucleotide primers derived from invasive plasmid antigen gene $(i p a H)$ sequence F[5' GCTGGAAAAACTCAGTGCCT3'] and $\mathrm{R}\left[5^{\prime}\right.$ CCAGTCCGTAAATTCATTCT3'] were selected for the study. The reaction mixture $(25 \mu \mathrm{l})$ consisted of template DNA $(5 \mu \mathrm{l}), 50 \mathrm{mM} \mathrm{KCl}, 10 \mathrm{mM} \mathrm{MgCl}_{2}$, gelatin $0.01 \%, 0.25 \mathrm{mM}$ each deoxynucleotide triphosphate, $50 \mathrm{pm}$ of each primer and 1 unit of Taq polymerase. The amplification was performed in a thermocycler (Perkin Elmer, Cetus, Norwalk Corporation) for 30 cycles $\left(94^{\circ} \mathrm{C}\right.$ for $60 \mathrm{~s}, 56^{\circ} \mathrm{C}$ for $120 \mathrm{~s}, 72^{\circ} \mathrm{C}$ for $60 \mathrm{~s}$ ) followed by a final extension at $72^{\circ} \mathrm{C}$ for $7 \mathrm{~min}$. A preheating step of $96-98^{\circ} \mathrm{C}$ for $10 \mathrm{~min}$ was included before the cycle started to prepare singlestranded DNA for PCR. Electrophoretic separation of amplified DNA $(10 \mu \mathrm{l})$ was performed on horizontal agarose $1 \%$ gels, stained with ethidium bromide (1\% aqueous solution) and visualised under ultraviolet light. 
The identity of the amplified band at the 424-bp region was confirmed by Southern hybridisation with specific $i p a H$ probes. Signals were visualised by chemiluminescence (ECL). In each batch of tests, suitable positive controls and negative bacterial and reagent controls were used. PCR was performed twice by two separate technicians in a dedicated room with new acid-washed glassware.

\section{Preparation of 'spiked' stool samples to determine the sensitivity of conventional culture method, probe hybridisation and PCR}

Stool samples negative for Shigella spp. were 'spiked' with a saline suspension of a representative strain of $S$. flexneri 2 in serial 10 -fold dilutions to give $2-\left(2 \times 10^{6}\right) \mathrm{cfu} / \mathrm{ml}$ to determine the detection limit for the organism by the three methods. Each serial dilution of the spiked stool samples was spread on to MacConkey agar and Hektoen agar, both directly and also after enrichment in Luria broth (LB) for 4-6 h. Four suggestive colonies from each plate were selected and tested by the API test and antisera (Denka Seikon) for Shigella spp. and EIEC strains.

Macro-colonies were obtained from each dilution of stool samples by applying the LB-enriched samples directly on to a nylon membrane; the membrane was placed on nutrient agar and incubated at $37^{\circ} \mathrm{C}$ overnight. The resulting colonies were tested by colony hybridisation with an ial probe as described previously.

PCR was performed three times with each dilution of spiked stool samples with direct stools, stools after enrichment in LB for $4-6 \mathrm{~h}$ or stools after DNA extraction, as template DNA in the PCR master mix. DNA extraction from stools was completed by a standard protocol [15] within $7 \mathrm{~h}$. Broth enrichment or DNA extraction would help to eliminate the natural inhibitors of the PCR reaction, which were present in the stool samples.

The sensitivity of each assay was defined as the lowest concentration of $S$. flexneri (in cfu) that yielded positive results for each of the three assays.

\section{Study population}

In this study, considering the proportion of interest, i.e., diarrhoeal cases presenting with frequent passage (more than three times in $24 \mathrm{~h}$ ) of stool with blood with mucus to be $40 \%$ (p) and clinical variations to be $15 \%$ of $40 \%$ (d), the sample size was calculated as 256 patients using the formula $\left(n=z^{2} \mathrm{pq} / \mathrm{d}^{2}, \mathrm{z}=\right.$ standard normal deviation and $q=1-p)$. A total of 300 children admitted to Dr B.C. Roy Children's Hospital with acute diarrhoea from Monday to Friday, Feb.-May 1999 were studied prospectively. Stool samples were collected from each child, irrespective of the history of antibiotic therapy, nature, severity and duration of the disease.
The history of intake of antimicrobial agents was noted but not revealed before processing of the samples.

\section{Processing of clinical samples}

Stool samples were immediately transported in Cary Blair medium to the microbiology laboratory of the institute and processed within $2 \mathrm{~h}$ of collection. Stools were enriched for $4-6 \mathrm{~h}$ in LB and plated on to MacConkey and Hektoen agar for identification of bacterial enteric pathogens by standard culture techniques. The enriched stool cultures were also blotted on to nylon membrane to obtain macro-colonies and colony hybridisation was performed with an ial probe as described previously. PCR was performed with the enriched stool samples as template DNA. The results obtained by the three different methods were compared and analysed.

A person was considered to have a shigella or EIEC infection (microbiologically confirmed cases) if these organisms were detected by any of the three methods. Patients for whom standard microbiological culture did not detect any enteropathogens including Shigella spp. or EIEC, but whose stool specimens contained ipaH sequences after PCR amplification or ial sequences after DNA hybridisation, were considered to have had shigella or EIEC infections, when the clinical presentation of the children suggested shigellosis or dysentery.

\section{Antimicrobial sensitivity pattern}

Antimicrobial susceptibility patterns of the isolated strains of Shigella spp. and EIEC, including untypable strains, were determined by the disk diffusion method following a standard protocol [16].

\section{HeLa cell invasion assay}

The strains that were identified as Shigella untypable (Sh OUT) by biochemical tests and serology, but showed positive results when detected by PCR and DNA hybridisation, were tested for epithelial invasion by the HeLa cell invasion assay following standard procedures [17].

\section{Statistical methods}

$\chi^{2}$ test with Yates correction or Fisher's exact test were used to compare the test results; $\mathrm{p}<0.05$ was considered significant.

\section{Results}

Determination of analytical specificity and sensitivity of the PCR assay

A collection of Shigella (64) and EIEC (7) strains isolated from children in Calcutta between 1990 and 
1997 was tested with the ipaH PCR system. Each of the isolates yielded an amplified band of $424 \mathrm{bp}$ with the system, the identity of which was confirmed by Southern hybridisation with an ipaH probe. Specificity of the primer pairs was established by testing nonShigella enteric bacterial DNA as a template for the PCR. The PCR assay with any species other than Shigella and EIEC failed to produce the characteristic fragments. Therefore, the PCR method used in this study was $100 \%$ specific. It could only identify all four serogroups of Shigella spp. and EIEC strains.

The sensitivity of this diagnostic method was determined by the number of organisms (expressed in $\mathrm{cfu} / \mathrm{ml}$ ) seeded into each $\mathrm{ml}$ of stool sample that could be detected by the respective method. In this study, experiments were conducted directly and after enrichment of stools inoculated with 10 -fold dilutions of $S$. flexneri 2 to determine the detection limits for the organism. The experiment with each dilution of organism was replicated three times and results were denoted as,,++++++ accordingly. A test system was considered sensitive to a dilution of organism when at least ++ (i.e., twice positive) results were recorded with the same dilution. Culture, probe hybridisation and PCR were employed for comparison of diagnostic methods (Table 1). The PCR was sensitive with direct stool samples with an inoculum size of $2 \times 10^{3} \mathrm{cfu} / \mathrm{ml}$. The detection limit of Shigella spp. in an enriched stool culture by PCR was $2-4 \times 10^{2} \mathrm{cfu} / \mathrm{ml}$, which was equivalent to $1-5 \mathrm{cfu}$ per PCR reaction. As expected, the sensitivity was decreased in the presence of a high level of background flora and in the presence of natural inhibitors of the stool samples, i.e., with direct stool samples. The detection limit remained more or less the same $\left(2 \times 10^{2} \mathrm{cfu} / \mathrm{ml}\right)$ when the total DNA content was extracted from the stool samples and used as template DNA in the PCR assay. Even after enrichment, the sensitivity of the culture method and nucleic acid hybridisation was found to be much lower than that of the PCR assay, being positive at $2 \times 10^{6} \mathrm{cfu}$ and $2 \times 10^{4} \mathrm{cfu} / \mathrm{ml}$ of stool suspension, respectively.

\section{Determination of identifiable shigella and EIEC infection in children from clinical stool samples}

There were 183 boys (61\%) and 117 girls (39\%) in the 300 children with acute diarrhoea. The median age was 17 months (minimum 1 month, maximum 60 months). A clinical diagnosis of dysentery was made in 126 children $(42 \%)$, who presented with frequent passage of stool with blood and mucus, abdominal pain, tenesmus and fever. Almost $50 \%$ of the children (151) had watery diarrhoea and $8 \%$ of the children (23) presented with only mucoid diarrhoea without blood.

Measuring sensitivity and specificity in clinical stool specimens is complicated by limitations in standard culture methods. With the culture method, Shigella spp. were isolated as the sole pathogen from 7.7\% (23 of 300 ) of acute childhood diarrhoea cases, of which $4.4 \%$ (1 of 23) were $S$. dysenteriae, $65.2 \%$ (15 of 23$) S$. flexneri, 4.4\% (1 of 23) S. boydii and 26\% (6 of 23) $S$. sonnei, respectively. The antibiotic sensitivity patterns showed resistance to four or more antibiotics such as ampicillin, tetracycline, trimethoprim-sulphamethoxazole and amoxicillin in $>70 \%$ of strains. Resistance to norfloxacin and ciprofloxacin was not observed in the present study. EIEC was isolated from 3 (1\%) of 300 diarrhoea cases and $\mathrm{O} 112 \mathrm{ac}$ was the predominant serotype.

Table 2 shows the combinations of results obtained by employing three different methods with enriched stool samples for the diagnosis of dysentery in 300 children. All three methods detected the infection in $24(8 \%)$ of 300 children with acute diarrhoea, of which EIEC was identified by culture in three cases. Culture and probe hybridisation detected $S$. flexneri type 3 in two samples which were negative by direct stool PCR, but when the

Table 1. Detection of S. flexneri 2 by culture, colony hybridisation and PCR in stool samples inoculated with various concentrations of the organism

\begin{tabular}{|c|c|c|c|c|c|c|}
\hline \multirow[b]{2}{*}{$\begin{array}{l}\mathrm{APC}^{* \dagger} \\
\text { S. flexneri }(\mathrm{cfu} / \mathrm{ml})\end{array}$} & \multicolumn{2}{|c|}{ Culture method } & \multirow[b]{2}{*}{$\begin{array}{c}\text { Colony hybridisation } \\
\text { by a probe }\end{array}$} & \multicolumn{3}{|c|}{ PCR } \\
\hline & Direct & $\begin{array}{l}\text { Enrichment } \\
\text { for } 4 \mathrm{~h}\end{array}$ & & direct & $\begin{array}{l}\text { after enrichment } \\
\text { for } 4 \mathrm{~h}\end{array}$ & $\begin{array}{l}\text { after DNA } \\
\text { extraction }\end{array}$ \\
\hline$\overline{0^{*}}$ & - & - & - & - & - & - \\
\hline 2 & - & - & - & - & - & - \\
\hline $2 \times 10^{1}$ & - & - & - & - & - & + \\
\hline $2 \times 10^{2}$ & - & - & - & - & +++ & +++ \\
\hline $2 \times 10^{3}$ & - & - & - & ++ & +++ & +++ \\
\hline $2 \times 10^{4}$ & - & - & ++ & +++ & +++ & +++ \\
\hline $2 \times 10^{5}$ & - & + & +++ & +++ & +++ & +++ \\
\hline $2 \times 10^{6}$ & ++ & +++ & +++ & +++ & +++ & +++ \\
\hline
\end{tabular}

- , three replica samples negative; +++ , three replica samples positive; ++ , two replica samples positive; + , one replica sample positive. *APC, aerobic plate count reported as the range of cfu, found after spread plating of $S$. flexneri 2 suspension (10 $\mu 1)$ in normal saline and incubation at $37^{\circ} \mathrm{C}$ for $24 \mathrm{~h}$.

${ }^{\dagger}$ At least three replicate samples of each dilution were analysed.

†Uninoculated sample used as a negative control. 
Table 2. Combination of results obtained by culture, probe hybridisation and PCR with enriched stool samples for the diagnosis of shigella or EIEC infection in 300 diarrhoeal children

\begin{tabular}{lccc}
\hline $\begin{array}{l}\text { Culture } \\
\mathrm{n}=26(8.7 \%)\end{array}$ & $\begin{array}{c}\text { Probe hybridisation } \\
\mathrm{n}=29(9.7 \%)\end{array}$ & $\begin{array}{c}\text { PCR after enrichment } \\
\mathrm{n}=46(15.3 \%)\end{array}$ & $\begin{array}{c}\text { Total }(\%) \text { with result } \\
\text { pattern } \mathrm{n}=48(16 \%)\end{array}$ \\
\hline$+^{*}$ & + & + & $24(8)$ \\
+ & + & - & $2(0.6)$ \\
- & + & + & $3(1)$ \\
- & - & + & $19(6.3)$ \\
\hline${ }^{*}$ Of 24 samples, Shigella & spp. were isolated from 21 samples and EIEC were isolated from 3
\end{tabular}
samples.

individual strain cultures were tested by PCR, they showed positive results. Again, PCR alone detected shigella or EIEC infection in 19 children $(6.3 \%)$ whose infection remained undiagnosed by the other two methods. Moreover, PCR could identify three strains that showed biochemical reactions identical to Shigella spp. as determined by the API test, but were nonagglutinable with commercially available antisera (Denka Seiken). These strains were designated as Shigella untypable strains (Sh OUT). Those strains also showed positive signals in autoradiograms when DNA hybridisation was performed with the ial probe.

The clinical symptoms of the children diagnosed by PCR alone (6.3\%) were suggestive of acute bacillary dysentery and were exactly same as the symptoms of children diagnosed by culture. Hence, in this study, the ipaH PCR in combination with standard bacteriology and colony hybridisation was used to determine microbiologically confirmed cases (MCC) of shigella and EIEC infection. Table 2 shows that a total of 48 children $(16 \%)$ had microbiologically confirmed shigella or EIEC infection. Of these 48 cases, 37 (77\%) presented with bloody mucoid diarrhoea, 9 children (19\%) initially had watery diarrhoea and subsequently bloody diarrhoea, and 2 children (4\%) presented with only mucoid diarrhoea.

Table 3 shows the concordance between positive stool culture and positive DNA hybridisation with positive stool PCR. Considering the $100 \%$ specificity and highest sensitivity $\left(2 \times 10^{2} \mathrm{cfu} / \mathrm{ml}\right)$ of the PCR test system with enriched stool samples (Table 1), the PCR diagnostic system should be taken as the gold standard for comparing the performance of PCR with that of the other two methods. Of 46 children (15.3\%) diagnosed as having dysentery by PCR, 22 were negative by culture and 19 were negative by DNA hybridisation assays. PCR failed to detect the infection in only two children who were diagnosed by both culture and hybridisation methods (false negative).

In those individuals with a positive stool culture, $92 \%$ (24 of 26) were stool PCR positive and in those with negative stool culture, $8 \%$ (22 of 274) were stool PCR positive. On the other hand, in those with a positive stool PCR, $52 \%$ (24 of 46 ) were stool culture positive and in those with negative stool PCR, 99\% (252 of
Table 3. Concordance between enriched stool culture, stool blot and colony hybridisation and enriched stool PCR

\begin{tabular}{lccc}
\hline & \multicolumn{2}{c}{ PCR result } & \\
\cline { 2 - 3 } Assay compared & Positive & Negative & Total \\
\hline Culture & & & \\
$\quad$ Positive & 24 & 2 & 26 \\
$\quad$ Negative & 22 & 252 & 274 \\
DNA hybridisation & & & \\
$\quad$ Positive & 27 & 2 & 29 \\
$\quad$ Negative & 19 & 252 & 271 \\
Total & 46 & 254 & 300 \\
\hline
\end{tabular}

254) were stool culture negative $\left(\chi^{2}\right.$ test, $\left.\mathrm{p}<0.05\right)$. There was a high degree of concordance between stool culture and stool PCR, but PCR confirmed more cases than did stool culture. Similarly, probe hybridisation detected 59\% (27 of 46) of positive stool PCR and 99\% (252 of 254) of negative stool PCR $(\mathrm{p}<0.05)$, establishing a concordance between stool blot hybridisation and stool PCR.

\section{Comparison of performance characteristics of different methods}

Table 4 presents a comparison of performance characteristics and results of evaluation of the three methods - i.e., enriched stool culture, enriched stool blot and colony hybridisation, and enriched stool PCR - used in this study for diagnosis of shigella or EIEC infection in children. For this evaluation, microbiologically confirmed cases (MCC) of shigella or EIEC infection was taken as standard and thus the sensitivity of culture, blot hybridisation and PCR assays was found to be $54 \%, 60 \%$ and $96 \%$, respectively.

Clinical diagnosis of bloody dysentery was also evaluated in this context. A total of 126 children were diagnosed clinically as having bloody dysentery and treated with antibiotics. Of 126 cases 37\% (46 of 126) were confirmed by one or more of the laboratory tests, i.e., actually had the disease. Of 174 non-dysentery cases only two children were confirmed as having shigellosis by stool PCR and presented with mucoid diarrhoea. Therefore, 99\% (172 of 174) of nondysentery cases were diagnosed correctly by clinical 
Table 4. Sensitivity, specificity, predictive values and agreement of enriched stool PCR, enriched stool blot with colony hybridisation, culture and clinical diagnosis of bloody dysentery in comparison to total microbiologically confirmed cases

\begin{tabular}{lccccc}
\hline Assay evaluated & $\begin{array}{c}\text { Sensitivity } \\
\text { (CI) }(\%)\end{array}$ & $\begin{array}{c}\text { Specificity } \\
(\%)\end{array}$ & $\begin{array}{c}\text { PPV } \\
(\%)\end{array}$ & $\begin{array}{c}\text { NPV } \\
(\%)\end{array}$ & $\begin{array}{c}\text { Agreement } \\
(\%)\end{array}$ \\
\hline Stool PCR & $96(94-98)$ & 100 & 100 & 99 & 99 \\
Colony hybridisation & $60(54-66)$ & 100 & 100 & 93 & 94 \\
Culture & $54(48-60)$ & 100 & 100 & 92 & 93 \\
Clinical diagnosis of & $96(94-98)$ & 68 & 37 & 99 & 73 \\
bloody dysentery & & & & & \\
\hline
\end{tabular}

CI, 95\% confidence interval; PPV, positive predictive value; NPV, negative predictive value.

methods as not having the disease. An agreement of $73 \%$ was observed between the clinical diagnosis and laboratory diagnosis.

\section{Characterisation of untypable Shigella strains}

To further characterise the three Shigella OUT strains, isolated solely from acute childhood diarrhoea cases, phenotypic and genotypic profiles including biochemical tests, serotyping with commercially available antisera, antibiotic susceptibility pattern, $\mathrm{HeLa}$ cell invasion assay, detection by ipaH PCR and detection by $i a l$ probe were analysed. When tested for plasmids these strains showed the presence of a large $220-\mathrm{kb}$ plasmid (Fig. 1) [18]. These strains may represent untypable variants of $S$. flexneri strains. The strains ( $S h$ OUT) were lactose non-fermenters, non-motile and oxidase-negative, but produced catalase, fermented

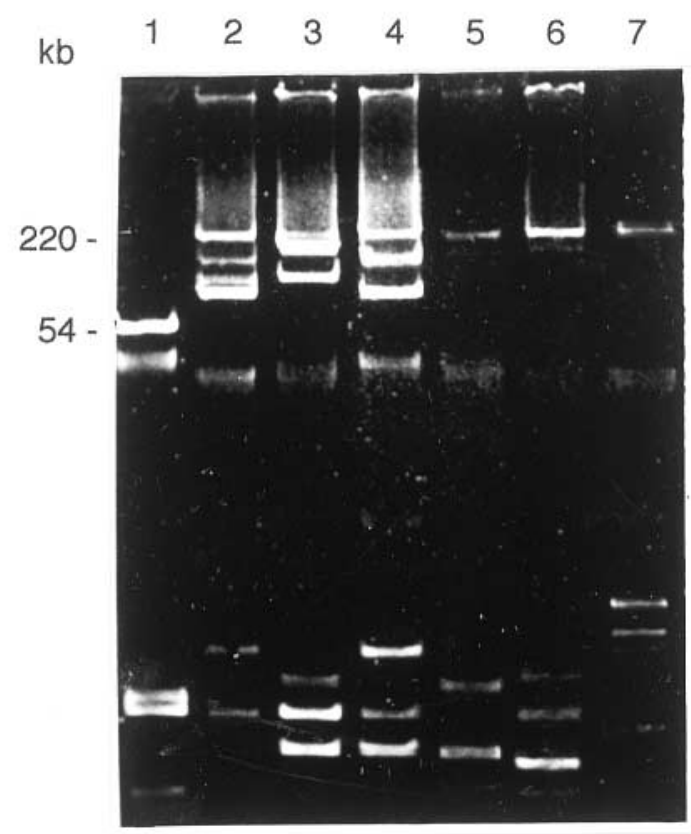

Fig. 1. Plasmid profiles of Shigella strains isolated solely from children with acute diarrhoea after agarose $1 \%$ gel electrophoresis of plasmid DNA from the strains. Lane 1, E. coli V517 (DNA size marker) [18]; 2, Sh OUT 1; 3, Sh OUT 2; 4, Sh OUT 3; 5, S. flexneri type 2; 6, $S$. flexneri type $3 ; 7, S$. sonnei. glucose and mannitol with only acid production without gas, and reduced nitrate. They were negative for indole production, citrate utilisation, $\mathrm{H}_{2} \mathrm{~S}$ production and lysine decarboxylation. They did not show agglutination with commercial antisera (Denka Seiken), but invaded HeLa cells, generated an amplified band in ipaH PCR and showed positive signals in the autoradiogram after colony blot hybridisation. They were resistant to ampicillin, co-trimoxazole, tetracycline and amoxicillin in the disk diffusion test.

\section{Discussion}

This PCR system was highly specific (100\%) for the diagnosis of shigella and EIEC infection. This system showed negative results with all bacterial strains tested other than Shigella spp. and EIEC, indicating high specificity. Similarly, as regards the sensitivity of the assay system, the PCR system was highly sensitive at very low bacterial concentration $\left(2 \times 10^{2} \mathrm{cfu} / \mathrm{ml}\right)$. In this respect, this PCR was $10^{2}$-fold more sensitive than the colony hybridisation assay and $10^{4}$-fold more sensitive than the conventional culture method for detecting Shigella spp.

When a new test is evaluated, analysis is done mostly on the efficiency of the new test in relation to currently used tests. In the present study, the ipaH PCR system was evaluated in comparison with the standard culture method and a probe hybridisation method for detecting shigella and EIEC infection. This study also validated the ability and performance of these three diagnostic methods to describe the true disease frequency in the paediatric population of Calcutta with acute diarrhoea.

The assay was extremely reliable, being able to detect 24 of 26 culture-confirmed shigella and EIEC infections in children; only two cases were missed by the PCR system. Furthermore, it also detected 22 culturenegative clinically important dysentery cases, indicating the high level of efficiency of the assay system. The frequency of dysentery cases in children with acute diarrhoea was $8.6 \%$ (26 of 300 ) by the culture method; but when other techniques were employed, the frequency of the disease was found to be $9.6 \%$ (27 of 300 ) by probe hybridisation and $15.3 \%$ (46 of 300 ) by 
PCR assay. Of 46 children diagnosed by PCR, only two children presented with mucoid diarrhoea and the other 44 had dysentery. Thus it was obvious that the highest percentage of diarrhoeal children $(15.3 \%)$ could be diagnosed as having this infection by PCR. The results presented in this study showed lower sensitivity of culture (54\%) and probe hybridisation (60\%) when compared with PCR assay (96\%).

In a study from Bangladesh [11], the culture method was $72 \%$ sensitive and $100 \%$ specific when compared with the ipaH PCR system, whereas in the present study the sensitivity of the culture method was found to be only $54 \%$. The relatively low sensitivity of the culture method in this study was thought to be due to the use of only two selective agar media for isolation of the Shigella spp. In the Bangladesh study at least three selective media were used. In a community-based study conducted in Thailand [10] the ipaH PCR system increased the rate of detection of Shigella spp. or EIEC by $37 \%$ over standard culture techniques. The latter study also reported that the PCR system increased the detection of Shigella spp. by more than three times compared with culture alone, among family contacts of dysentery patients - although family contacts were not followed up in the present study. Further research on asymptomatic shigella infection in the population of Calcutta, where shigellosis is endemic, would generate important information that might contribute to understanding the transmission of this organism.

This ipaH assay system amplifies the sequence present on both the invasion plasmid and the chromosome, has been shown to detect Shigella and EIEC organisms that have lost the invasion essential plasmid. Hence this assay is likely to identify a false-negative sample or strain as determined by a plasmid-dependent assay system [4]. This system is also useful for diagnosing infections after antibiotic therapy in cases of treatment failure, as documented by other workers [8]. They could identify the infection in $5(10.6 \%)$ of 47 antibiotic-treated cases, which were negative by culture and by ial probe hybridisation. In the present study, of 22 culture-negative and PCR-positive cases, 18 had a history of antibiotic intake. This again explains the advantage of using the PCR assay over culture. The reason why repeated PCR stool assay missed two culture-proven shigellosis cases could not be explained. The presence of some PCR inhibitors in stool or low numbers of the organism may have caused this result.

The present study showed that the PCR assay was not only highly sensitive, but could provide a result on the same day that a specimen was submitted for evaluation, a potential advantage during outbreak investigations. In the present study, the mean duration required for the various assay systems from submission of samples to the clinical laboratory to report writing was $7 \mathrm{~h}$ (SD 0.8) for enriched stool PCR, $34 \mathrm{~h}$ (SD 5.6) for probe hybridisation and $42 \mathrm{~h}$ (SD 4.3) for culture. So the rapidity of the PCR method also made it convenient for use in a clinical laboratory for diagnosing shigellosis, although a simultaneous culture is always recommended for clinically important samples, to determine the antimicrobial susceptibility of the locally isolated strains. This would ensure rapid results from clinical samples containing $10^{2} \mathrm{cfu}$ of Shigella spp. or EIEC $/ \mathrm{ml}$ and would enable prompt implementation of targeted antibiotic therapy, particularly for infections with resistant strains.

Further three strains ( 3 of $300 ; 1 \%$ ), that were untypable by conventional techniques could be identified by this PCR system. Additional characterisation of strains by biotyping, antibiogram analysis, plasmid profiling and intracellular epithelial invasion assay suggested little genetic diversity among the strains. The plasmid profiles (Fig. 1) of the three strains showed the presence of multiple copies of plasmids in the strains. Plasmids of $220 \mathrm{~kb}$ are of particular interest, because usually the invasive phenotype of the organism is mediated by genes carried on these larger plasmids, as documented in previous studies $[19,20]$. Further work is in progress to characterise the strains with polyclonal antisera prepared to the whole bacterial cells and to determine antigenic similarity among strains. These strains might represent a new serotype of $S$. flexneri, which could have been missed if the PCR system had not been used for diagnosis. The emergence of new serotypes of $S$. dysenteriae and $S$. flexneri has been reported in previous studies [21, 22].

There have been some reports in which nested PCR methods have been used for detection of Shigella spp. in foods, e.g., lettuce, vegetables, mayonnaise [5]. However, the choice as to whether the single PCR or nested PCR would be used depends on the facilities available to the laboratory, the nature of the sample tested and also on the endemicity of the disease in that field situation. Usually, in a highly endemic area a large number of organisms are present in the stool of the patient, so the single PCR would suffice to diagnose the infection in an individual, whereas nested PCR should be used to identify the organism in food materials, where the numbers of the organism are expected to be less. However, if only the single PCR is used enrichment must be used to produce a sufficient increase in the number of Shigella bacteria as well as dilution of the natural PCR inhibitors present in the stool samples.

In conclusion, the ipaH PCR assay performed with enriched stool cultures is a highly sensitive and specific, rapid, simple and convenient test. It is useful if employed in epidemiological studies of dysentery. Moreover, it is able to identify a number of serologically untypable strains, which may indicate new serotypes of $S$. flexneri. Such studies may also help to determine whether a molecular approach can 
identify changes in the epidemiology of shigellosis in a particular community.

We thank Dr J.P. Nataro, Center for Vaccine Development, Baltimore, MD, USA for supplying the ial probe-containing strains and control strains. The support of Dr U. Mitra, Senior Research Officer, Clinical Division, all research fellows and post-graduate students is gratefully acknowledged.

\section{References}

1. World Health Organization: Programme for control of diarrhoeal diseases. A manual for the treatment of acute diarrhoea. Document WHO/CDD/SER/80.2. WHO, Geneva. 1984.

2. Small PL, Falkow S. Development of a DNA probe for the virulence plasmid of Shigella spp and enteroinvasive Escherichia coli. In: Lieve L, Bonventre PF, Morello JA, Silver SD, Wu WC (eds) Microbiology. Washington, DC, American Society for Microbiology. 1986: 121-124.

3. Venkatesan M, Buysse JM, Vandendries EV, Kopecko DJ Development and testing of invasion-associated DNA probes for detection of Shigella spp and enteroinvasive Escherichia coli. J Clin Microbiol 1988; 26: 261-266.

4. Venkatesan M, Buysse JM, Kopecko DJ. Use of Shigella flexneri ipaC and ipaH gene sequences for the general identification of Shigella spp. and enteroinvasive Escherichia coli. J Clin Microbiol 1989; 27: 2687-2691.

5. Lindqvist R. Detection of Shigella spp. in food with a nested PCR method - sensitivity and performance compared with a conventional culture method. J Appl Microbiol 1999; 86: 971-978.

6. Frankel G, Riley L, Giron JA et al. Detection of Shigella in feces using DNA amplification. J Infect Dis 1990; 161: $1252-1256$

7. Houng HS, Sethabutr O, Echeverria P. A simple polymerase chain reaction technique to detect and differentiate Shigella and enteroinvasive Escherichia coli in human feces. Diagn Microbiol Infect Dis 1997; 28: 19-25.

8. Sethabutr O, Venkatesan M, Murphy GS, Eampokalap B, Hoge $\mathrm{CW}$, Echeverria P. Detection of Shigellae and enteroinvasive Escherichia coli by amplification of the invasion plasmid antigen H DNA sequence in patients with dysentery. $J$ Infect Dis 1993; 167: 458-461.

9. Sethabutr O, Echeverria P, Hoge CW, Bodhidatta L, Pitavangsi C. Detection of Shigella and enteroinvasive Escherichia coli by
PCR in the stools of patients with dysentery in Thailand. $J$ Diarrhoeal Dis Res 1994; 12: 265-269.

10. Gaudio PA, Sethabutr O, Echeverria P, Hoge CW. Utility of a polymerase chain reaction diagnostic system in a study of the epidemiology of shigellosis among dysentery patients, family contacts and well controls living in a shigellosis-endemic area. J Infect Dis 1997; 176: 1013-1018.

11. Islam MS, Hossain MS, Hasan M et al. Detection of Shigellae from stools of dysentery patients by culture and polymerase chain reaction techniques. J Diarrhoeal Dis Res 1998; 16: $248-251$.

12. Tornieporth NG, John J, Salgado K et al. Differentiation of pathogenic Escherichia coli strains in Brazilian children by PCR. J Clin Microbiol 1995; 33: 1371-1374.

13. Dutta S, Sinha Mahapatra T, Dutta P, Mitra U, Dasgupta S. Serotypes and antimicrobial susceptibility patterns of Shigella species isolated from children in Calcutta, India. Eur J Clin Microbiol Infect Dis 1998; 17: 298-299.

14. Kado CI, Liu S-T. Rapid procedure for detection and isolation of large and small plasmids. $J$ Bacteriol 1981; 145: $1365-1373$.

15. Maniatis T, Fritsch EF, Sambrook J. Molecular cloning: a laboratory manual. Cold Spring Harbor, NY, Cold Spring Harbor Laboratory. 1982.

16. National Committee for Clinical Laboratory Standards: Performance standards for antimicrobial disk susceptibility tests. Approved standard M2-M3. NCCLS, Villanova, PA. 1984.

17. Day NP, Scotland SM, Rowe B. Comparison of an HEP-2 tissue culture test with the Sereny test for detection of enteroinvasiveness in Shigella spp. and Escherichia coli. J Clin Microbiol 1981; 13: 596-597.

18. Macrina FL, Kopecko DJ, Jones KR, Ayers DJ, McCowen SM. A multiple plasmid-containing Escherichia coli strain: convenient source of size reference plasmid molecules. Plasmid 1978; 1: 417-420.

19. Hale TL. Genetic basis of virulence in Shigella species. Microbiol Rev 1991; 55: 206-224.

20. Sansonetti PJ. Genetic and molecular basis of epithelial cell invasion by Shigella species. Rev Infect Dis 1991; 13 Suppl 4: S285-S292.

21. Kuijper EJ, van Eeden A, de Wever B, van Ketel R. Dankert J. Nonserotypeable Shigella dysenteriae isolated from a Dutch patient returning from India. Eur $J$ Clin Microbiol Infect Dis 1997; 16: 553-554.

22. Trevejo RT, Abbott SL, Wolfe MI, Meshulam J, Yong D, Flores GR. An untypeable Shigella flexneri strain associated with an outbreak in California. J Clin Microbiol 1999; 37: 2352-2353. 